\title{
Impression order effects as a function of the personal relevance of the object of description*
}

\author{
JOHN H. BRINK \\ Purdue University, West Lafayette, Indiana 47907
}

\begin{abstract}
The influence of different target stimuli on impression order effects was tested. Sixty Ss evaluated bivalent sets of personality trait adjectives which purportedly described a hypothetical stranger, the $E$, or the Ss themselves. Under unwarned recall conditions, variations in the object of description significantly influenced impression order effects $(p<.01)$. It was suggested that this effect may have been a function of attention decrements and implicit evaluations associated with various levels of personal relevance of the impression formation task. Analyses of adjective recall supported the verbal memory hypothesis of impression formation for only the LH sets in the forewarned recall condition. Recall analyses, however, suggested the importance of recall measurement criteria used in tests of the verbal memory hypothesis.
\end{abstract}

Various types of experimental stimuli have been used to investigate the effects of informational sequence on judgments of attractiveness or likability. Under normal experimental conditions, the serial presentation of personality trait adjectives has been found to elicit impressions marked by primacy effects (cf. Anderson, 1965; Anderson \& Barrios, 1961; Anderson \& Hubert, 1963; Anderson \& Norman, 1964; Asch, 1964; Stewart, 1965; Tesser, 1968). Under similar conditions of stimulus presentation, order effects in responses to attitudinal material were negligible (Byrne, Lamberth, Palmer, \& London, 1969; Byrne \& London, 1966; Jones \& Wein, 1972). Impression judgments in responses to series of personal evaluations, however, have been characterized by recency effects (Aronson \& Linder, 1965; Tognoli \& Keisner, 1972).

An examination of the experimental procedures used in these order effect studies indicates that the object of description varied with the types of stimulus materials employed. Adjective stimuli typically provided Ss with descriptions of hypothetical strangers. Attitudinal information represented the beliefs of anonymous fellow students. The sequential presentation of personal evaluations involved the Ss themselves as the objects of description. The confounding of stimulus material and object of description in these previous studies makes it impossible to identify the extent to which each variable is responsible for the differing order effects obtained. The present experiment attacked this methodological difficulty by observing the influence of various descriptive objects on order effects in responses to a single type of stimulus material.

Griffitt, Byrne, and Bond (1971) manipulated the personal relevance of an impression formation task by varying the stimulus person to whom an adjective description referred. Consistent with this approach, sets of personality trait adjectives in the present experiment

*This research was supported in part by Research Grant GS-2752 from the National Science Foundation to Donn Byrne, Principal Investigator. were used to describe a hypothetical stranger, the E, or the $\mathrm{S}$ himself. On the basis of the experimental results mentioned above, it was hypothesized that the magnitude of primacy effects decreases as the level of personal relevance increases. Primacy effects were expected in a low-relevance task in which Ss evaluated descriptions of a hypothetical stranger. In contrast, the high-relevance task in which Ss received descriptions of themselves was predicted to result in judgments marked by recency effects. Intermediate order effects were expected at the moderate level of personal task relevance.

A secondary purpose of the present study was to explore the relationship between impressions of adjective set favorability and memory of impression-inducing stimuli. A number of investigators have considered impression judgments to be a function of the verbal memory of specific impression-inducing stimuli (Chalmers, 1969, 1971; Jones \& Goethals, 1971; Jones, Rock, Shaver, Goethals, \& Ward, 1968). In spite of the plausibility of this verbal memory hypothesis, several studies have demonstrated a lack of consistent relationships between impressions or opinions and informational content retention (Anderson \& Hubert, 1963; Greenwald, 1968; Insko, 1964; Miller \& Campbell, 1959; Watts \& McGuire, 1964). From visual inspection of serial recall curves, Anderson and Hubert (1963) concluded that, for both the unwarned and forewarned recall conditions of an impression formation task, impression memory and verbal memory involve distinct psychological processes. Chalmers $(1969,1971)$ has expressed skepticism about this conclusion. For example, he noted that in Anderson and Hubert's (1963) forewarned recall condition, impression recency effects did coincide with recall recency effects. Chalmers (1969) suggested that impression judgments and verbal memory do interact, at least for conditions of forewarned recall. Statistical analyses of the relationship between evaluative judgments and verbal recall were undertaken in order to further examine the role of verbal memory in impression formation. 
Table 1

Means and Standard Deviations of Impression Order Effects Over Levels of Personal Relevance and Recall Instruction

\begin{tabular}{lrrrrr}
\hline \multirow{2}{*}{$\begin{array}{c}\text { Personal } \\
\text { Relevance } \\
\text { (Description) }\end{array}$} & \multicolumn{2}{c}{ Unwarned Recall } & & \multicolumn{2}{c}{ Forewarned Recall } \\
\cline { 2 - 3 } \cline { 6 - 6 } & Mean & SD & & Mean & SD \\
\hline Low (Stranger) & +1.60 & 1.85 & & -.60 & 1.64 \\
Moderate (E) & +.20 & 1.64 & & -.50 & 1.73 \\
High (S) & -.05 & 1.43 & & -.60 & 1.64 \\
\hline
\end{tabular}

Note-Positive and negative order effect means represent primacy and recency effects, respectively.

\section{METHOD}

\section{Subjects}

Sixty students ( 30 males and 30 females) participated in the experiment in order to satisfy requirements for an introductory psychology course. They were randomly assigned to three groups of 20 each ( 10 males and 10 females), with each group receiving different instructions relating to the personal relevance of the experimental task.

\section{Stimuli}

A total of 16 favorable $(\mathrm{H})$ and 16 unfavorable $(\mathrm{L})$ adjectives were taken from Anderson's (1968a) normative list of adjective likability. The $H$ adjectives ranged in value from 4.92 to 5.73 , with a mean of 5.23 . The $L$ adjectives ranged in value from .48 to 1.30 , with a mean of .95 . The adjectives were organized into four experimental sets, with eight adjectives in each set. Two HL sets consisted of four $\mathrm{H}$ adjectives followed by four $\mathrm{L}$ adjectives. This order of favorability was reversed in two LH sets.

\section{Design}

A 3 by 2 analysis of variance was used to test for differences in impression order effects across three levels of personal relevance and two within-S levels of recall instruction. The relationship between adjective recall and set favorability ratings was measured separately for the unwarned and forewarned recall conditions. In both conditions a 3 by 2 by 2 by 2 analy sis of variance was used to test for differences in the number of adjectives recalled over three levels of personal relevance, two levels of set order, two levels of impression favorability, and two within-S levels of adjective valence.

\section{Procedure}

The Ss' task was to form an impression of each adjective set and to evaluate each set in terms of its descriptive favorability. The adjectives in each set were read by the $E$ at the rate of approximately one every $3 \mathrm{sec}$. Ss usually indicated their impression of set favorability within $5 \mathrm{sec}$ after the presentation of the last adjective in each set. A delay interval of approximately $45 \mathrm{sec}$ intervened between the Ss' response to one adjective set and the introduction of the next set. Ss were instructed to consider each adjective set separately from the others. Each $\mathrm{S}$ was tested individually in sessions that lasted about $20 \mathrm{~min}$.

Judgments of each set were made on separate pages of booklets provided to the Ss. Each page contained a horizontal 8-point favorability scale. Ss responded by encircling a number from 1 to 8 , with 1 corresponding to highly unfavorable and 8 to highly favorable. An identifying label was placed by each number using the various combinations of favorable and unfavorable with highly, considerably, moderately, and slightly as modifiers.

Ss received four experimental sets in one of the following set presentation sequences: HL-LH-HL-LH; HL-LH-LH-HL; LH-HL-HL-LH; or LH-HL-LH-HL. For each one of these four set presentation orders, the $16 \mathrm{H}$ and $16 \mathrm{~L}$ adjectives were randomly distributed in five different ways. The Ss within each level of task relevance were randomly assigned to 1 of the 20 (four set presentation orders by five independent word orders) different stimulus configurations. These 20 stimulus patterns were identical for each of three between-S levels of task relevance. A practice set of eight neu tral adjectives with likability mean of 3.37 and range of 2.37 to 3.84 was presented to each $S$ prior to his receipt of the four experimental sets.

Personal relevance was varied over three experimental conditions by using three different objects of description. Ss were informed that the personality trait adjective sets described a hypothetical stranger, the $\mathrm{E}$, or the Ss themselves. To account for the contradictory nature of the adjectives within each set, the Ss were told that each adjective was contributed by a different person. In the hypothetical stranger condition, Ss were told to imagine that the information had been given by different people acquainted with the stranger. In the $E$ description condition, Ss were told that the adjective stimuli had been used by the E's former introductory psychology students in a teacher evaluation questionnaire. In the S description condition, the Ss were told that fellow students had used the adjectives to describe the $S$ on the basis of each S's responses to a 52-item attitude questionnaire administered early in the semester. In this condition Ss were given about $60 \mathrm{sec}$ to reexamine their previously completed attitude questionnaire in order to reinforce their belief in the cover story.

To prevent recall requests from interfering with the hypothesized relationship between task relevance and impression order effects, the first two experimental sets were administered under conditions of unwarned recall. Immediately after evaluating the second experimental adjective set, Ss were asked without previous warning to write down as many adjectives as they could remember from the second set. Although no recall requests were made for the first experimental set, impression responses to the first and second sets were conceptually identical, in that they were both unaffected by recall requirements. Prior to the presentation of both the third and fourth experimental adjective sets, Ss were forewarned that they would have to recall the adjectives within the next set immediately after they had given their evaluation of that set. In this forewarned recall condition, Ss recalled the adjectives of two different sets, whereas recall was limited to only one set in the unwarned recall condition.

For both unwarned and forewarned recall conditions, Ss wrote the recalled adjectives below the judgmental likability scale in whatever order they could remember them. Extra-set recall intrusions were deleted from the analysis of recall results.

\section{RESULTS}

\section{Impression Order Effects}

Impression order effects were measured as the difference in each S's responses to the HL and LH sets in the HL minus LH direction. Table 1 presents the mean impression order effects for the various levels of personal relevance and recall instruction. The differential influence of personal relevance in the two recall conditions was reflected by a significant Personal Relevance by Recall Instructions effect $(F=3.39$, $\mathrm{df}=2 / 57, \mathrm{p}<.05$ ). As predicted, the effect of personal relevance on impression order effects in the unwarned recall condition was also significant $(F=5.75, d f=2 / 57$, $\mathrm{p}<.01$ ), with differences in the direction of decreasing primacy with increasing personal relevance. A Newman-Keuls analysis of these impression order effects in the unwarned recall condition indicated that the 
primacy effect in the low-relevance task was significantly different from the order effects obtained in the moderate- and high-personal-relevance condition $(p<.01)$. The order effects in these two later conditions did not differ significantly. For the forewarned recall condition, personal relevance had no apparent influence on impression order effects $(F<1)$.

The significance of primacy and recency effects within each relevance and recall condition was tested with respect to independent variance estimates. For the unwarned recall condition the primacy effect in the low-relevance task was significant $(F=15.41, \mathrm{df}=1 / 18$, $\mathrm{p}<.01$ ), whereas the primacy and recency effects in the moderate- and high-relevance tasks were both negligible, $\mathrm{F}<1$ in both cases. In the warned recall condition the recency effects in low-, moderate-, and high-relevance tasks all failed to reach significance $(F=3.41,1.73$, and 2.72 , respectively, df $=1 / 18$ in all cases, $p<.08, .21$, and .12 , respectively). The recency effect over all three of these groups combined, however, was significant $(\mathrm{F}=6.93, \mathrm{df}=1 / 57, \mathrm{p}<.05)$.

\section{Impression and Recall Relationship}

For the HL and LH sets of the unwarned and forewarned recall conditions, Table 2 presents the mean number of $\mathrm{H}$ and $\mathrm{L}$ adjectives recalled by $\mathrm{Ss}$ with favorable and unfavorable set impressions. Favorable and unfavorable impressions were defined as those evaluations which fell above and below the mean impression response for each specific level of personal relevance and set order.

According to the verbal memory hypothesis, Ss with favorable set impressions should recall more positive adjectives and fewer negative adjectives than $\mathrm{Ss}$ with unfavorable set impressions. In the unwarned recall condition, a significant Set Impression by Adjective Valence interaction indicated that adjective recall was in a direction contrary to predictions of the verbal memory hypothesis $(F=4.26, \mathrm{df}=1 / 48, \quad \mathrm{p}<.05)$. This interaction was not influenced by set order, as the Set Order by Set Impression by Adjective Valence effect was negligible $(F<1)$.

In the forewarned recall condition, the Set Impression by Adjective Valence interaction was nonsignificant $(\mathrm{F}<1)$. This interaction, however, differed as a function of set order, as indicated by the Set Order by Set Impression by Adjective Valence interaction $(F=5.9$, $\mathrm{df}=1 / 108, \mathrm{p}<.05)$. Simple effects analyses demonstrated that the Set Impression by Adjective Valence interaction was nonsignificant for $\mathrm{HL}$ sets $(F=1.53, \mathrm{df}=1 / 108, \mathrm{n} . \mathrm{s}$.). For the LH sets, however, this interaction was significant in the direction predicted by the verbal memory hypothesis $(F=4.24, \mathrm{df}=1 / 108$, $\mathrm{p}<.05)$. These two simple interactions are presented in the right half of Table 2 . It should be mentioned that the Task Relevance by Set Impression by Set Order effects were nonsignificant for both unwarned and forewarned recall conditions $(F=1.49$ and .80$)$.
Table 2

Mean Number of Favorable (H) and Unfavorable (L) Adjectives Recalled Over Levels of Impression Favorability, Set Order, and Recall Instruction

\begin{tabular}{|c|c|c|c|c|}
\hline \multirow{2}{*}{$\begin{array}{c}\text { Set } \\
\text { Impression }\end{array}$} & \multicolumn{2}{|c|}{ Unwarned Recall } & \multicolumn{2}{|c|}{ Forewarned Recall } \\
\hline & $\mathbf{H}$ & $\mathbf{L}$ & $\mathbf{H}$ & $\mathrm{L}$ \\
\hline & \multicolumn{4}{|c|}{ HL Set Order } \\
\hline $\begin{array}{l}\text { Favorable } \\
\text { Unfavorable }\end{array}$ & $\begin{array}{r}.78 \\
1.78\end{array}$ & $\begin{array}{l}1.53 \\
2.00\end{array}$ & $\begin{array}{l}1.46 \\
1.78\end{array}$ & $\begin{array}{l}2.64 \\
2.45\end{array}$ \\
\hline & \multicolumn{4}{|c|}{ LH Set Order } \\
\hline $\begin{array}{l}\text { Favorable } \\
\text { Unfavorable }\end{array}$ & $\begin{array}{l}1.20 \\
1.48\end{array}$ & $\begin{array}{l}1.51 \\
1.48\end{array}$ & $\begin{array}{l}2.68 \\
2.18\end{array}$ & $\begin{array}{l}1.79 \\
2.05\end{array}$ \\
\hline
\end{tabular}

For each level of set order and recall instruction, correlational analyses provided a further specification of the relationship between impression favorability and the number of favorable and unfavorable adjectives recalled. In each experimental condition, the direction of the correlation corresponded to the direction of mean recall differences (shown in Table 2) between Ss with positive and negative impressions. None of these correlations, however, reached statistical significance.

\section{DISCUSSION}

The predicted relationship between the object of description and impression order effects was verified under conditions free of interference from recall requirements. As hypothesized, increases in personal relevance of the descriptive object were associated with a significant decrease in the strength of primacy order effects in the unwarned recall condition. The influence of different target stimuli on impression order effects in the context of a single type of stimulus material suggests that the object of description may partially account for the pattern of order effects obtained in previous investigations. The present experimental design, along with a similar approach introduced by Griffitt et al (1971), represents a useful extension of the adjective trait paradigm which has typically been restricted to descriptions of hypothetical strangers.

Two recent explanations of impression order effects can account for the pattern of results obtained in the present study. According to an attention decrement hypothesis, primacy effects in a hypothetical stranger task are caused by the decreasing attention given to each successive item in a serially presented adjective set (Anderson, 1965; Anderson \& Barrios, 1961; Anderson \& Hubert, 1963; Stewart, 1965). With high levels of task relevance, however, the personal salience of each informational item may preclude attention decrements. Considered in terms of Anderson's proportional change model for sequential presentation (Anderson, 1965, 1968b; Anderson \& Hovland, 1957; Anderson \& Hubert, 1963), attention equalization would even be sufficient to account for the slight recency effect obtained in the self-descriptive condition. 
Byrne, Lamberth, Palmer, and London (1969) demonstrated that responses to sequentially presented attitudinal stimuli were marked by recency effects when Ss were instructed to make covert evaluative responses after receipt of each successive attitude. These investigators specifically suggested that the tendency to make this type of implicit evaluative response would be more probable when the $S$ himself is being evaluated than when the $\mathrm{S}$ listens to adjective descriptions of a hypothetical stranger. The impression order effects obtained in the present study vary in a direction consistent with this suggestion.

The conclusions reached by Anderson and Hubert (1963) regarding the relationship between impression memory and verbal memory were generally supported by the present results. The analysis of variance tests indicated that, for the unwarned recall condition, a significant Set Impression by Adjective Valence interaction could be attributed to the fact that recall was in a direction contrary to predictions of a verbal memory hypothesis of impression formation. In support of Chalmer's (1969) suggestions, however, the Impression by Adjective Valence interaction for LH sets in the forewarned recall condition was significant and the differences were in a direction consistent with the verbal memory hypothesis. Yet, even in this instance, the correlations between impression favorability and $\mathbf{H}$ and $\mathbf{L}$ adjective recall failed to reach statistical significance.

Extra-set recall intrusions were excluded from recall analyses in both the present study and the study by Anderson and Hubert (1963). The verbal memory hypothesis assumes, however, that evaluative judgments are a function of the scale values of the information present in the verbal memory at the moment the impression response is given. Since extra-set intrusions are a part of the verbal memory, their deletion may have served to bias results against the verbal memory hypothesis. The relationship between impression and recall in the present study was reanalyzed, therefore, with extra-set recall intrusions included. In two instances, however, extra-set intrusions were not included in these analyses because they were evaluatively neutral adjectives from the preliminary practice set. As suspected, the additional analyses yielded results somewhat more compatible with the verbal memory hypothesis. First, although the interaction between set impression and adjective valence in the unwarned recall condition was still in a direction contrary to the verbal memory hypothesis, it was no longer significant $(F=2.50, \quad d f=1 / 48, \quad p>.10)$. Second, in the forewarned recall condition the correlations of $\mathrm{LH}$ set impressions with $\mathrm{H}$ and $\mathrm{L}$ adjective recall were now +.253 and -.110 , respectively. In the former instance, this correlation fell just short of significance by a two-tailed test $(\mathrm{p}<.06, \mathrm{df}=58)$.
With the additional analyses, the overall results still provide very little support for the verbal memory hypothesis. Two issues, however, argue against completely dismissing the verbal memory approach. First, the original analysis of variance tests, as well as the correlational tests using extra-set recall, did indicate a positive relationship between impression and recall for at least the LH sets in the forewarned recall condition. Second, if extra-set memory does influence impression judgments, the deletion of extra-set recall in previous research misrepresented the relationship between impressions and verbal memory. There was relatively little opportunity for operation of extra-set memory processes in the present study because only five adjective sets were used. With 80 and 30 experimental sets in the experiments reported by Anderson and Hubert (1963), however, it seems much more likely that extra-set adjective memory would have influenced impression judgments.

\section{REFERENCES}

Anderson, N. H. Primacy effects in personality impression formation using a generalized order effect paradigm. Journal of Personality \& Social Psychology, 1965, 2, 1-9.

Anderson, N. H, Likeableness ratings of 555 personality-trait words. Journal of Personality \& Social Psychology, 1968a, 9, 27 2-279.

Anderson, N. H. A simple model for information integration. In R. P. Abelson, E. Aronson, W. J. McGuire, T. M. New comb, M. J. Rosenberg, and P. H. Tannenbaum (Eds.), Theorie of cognitive consistency: $A$ source-book. Chicago: RandMcNally, 1968b. Pp. 731-743.

Anderson, N. H., \& Barrios, H. H. Primacy effects in personality impression formation. Journal of Abnormal \& Social Psychology, 1961, 63, 346-350.

Anderson, N. H., \& Hovland, C. I. The representation of order effects in communication research. In C. I. Hovland (Ed.), The order of presentation in persuasion. New Haven: Yale University Press, 1957.

Anderson, N. H., \& Hubert, S. Effects of concomitant verbal recall on order effects in personality impression formation. Journal of Verbal Learning \& Verbal Behavior, 1963, 2, 379-391.

Anderson, N. H., \& Norman, H. Order effects in impression formation in four classes of stimuli. Journal of Abnormal \& Social Psychology, 1964, 69, 467-471.

Aronson, E., \& Linder, D. Gain and loss of esteem as determinants of interpersonal attractiveness. Journal of Experimental Social Psychology, 1965, 1, 156-171.

Asch, S. Forming impressions of personality. Journal of Abnormal \& Social Psychology, 1946, 41, 258-290.

Byrne, D., Lamberth, J., Palmer, J., \& London, O. Sequential effects as a function of explicit and implicit interpolated attraction responses. Journal of Personality \& Social Psychology, 1969, 13, 70-78.

Bryne, D., \& London, $O$. Primacy-recency and the sequential presentation of attitudinal stimuli. Psychonomic Science, $1966,6,193-194$.

Chalmers, D. K. Meanings, impressions, and attitudes: A model of the evaluation process. Psychological Review, 1969, 76, 450-460.

Chalmers, D. K. Repetition and order effects in attitude formation. Journal of Personality \& Social Psychology, 1971, 17, 219-228.

Greenwald, A. G. Cognitive learning, cognitive response to persuasion, and attitude change. In A. G. Greenwald, T. C, Brock, and T. M. Ostrom (Eds.), Psychological foundations of attitudes. New York: Academic Press, 1968.

Griffitt. W., Byrne, D., \& Bond, M. H. Proportion of positive adjectives and personal relevance of adjectival descriptions as determinants of attraction. Journal of Experimental Social Psychology, 1971, 7, 111-121.

Insko, C. A. Primacy versus recency in persuasion as a function of the timing of arguments and measures. Journal of Abnormal \& Social Psychology, 1964, 69, 381-391. 
Jones, E. E., \& Goethals, G. R. Order effects in impression formation: Attribution context and the nature of the entity. Morristown, N.J: General Learning Press, 1971.

Jones, E. E., Rock, L., Shaver, K. G., Goethals, G. R., \& Ward, L. M. Pattern of performance and ability attribution: An unexpected primacy effect. Journal of Personality \& Social Psychology, 1968, 10, 317-340.

Jones, E. E., \& Wein, G. A. Attitude similarity, expectancy violation, and attraction. Journal of Experimental Social Psychology, 1972, 8, 222-235.

Miller, N., \& Campbell, D. T. Recency and primacy in persuasion as a function of the timing of speeches and measurements. Journal of Abnormal \& Social Psychology, 1959, 59, 1-9.

Stewart, R. Effect of continuous responding on the order effect in personality impression formation. Joumal of Personality \& Social Psychology, 1965, 1, 161-165.
Tesser, A. Differential weighting and directed meaning as explanations of primacy in impression formation. Psychonomic Science, 1968, 11, 299-300.

Tognoli, J., \& Keisner, R. Gain and loss of esteem as determinants of interpersonal attraction: $A$ replication and extension. Journal of Personality \& Social Psychology, 1972, $23,201 \cdot 204$

Watts, W., \& McGuire, W. Persistence of induced opinion change and retention of the inducing message contents. Journal of Abnormal \& Social Psychology, 1964, 68, 233-241.

(Received for publication November 16, 1973; revision received January $28,1974$. ) 